\title{
Alloscirtetica labiatarum
}

(Ducke, 1910) comb. nov. e nota descritiva

(Hymenoptera, Anthophoridae) $^{1}$

Alloscirtetica labiatarum

(Ducke, 1910) comb. nov. and descriptive note

(Hymenoptera, Anthophoridae).

DANÚNCIA URBAN $^{2}$

Descrita do Ceará, Eucera labiatarum Ducke, 1910, foi alocada com dúvidas, por Michener, LA Berge \& Moure (1955), no gênero Gaesischia, proposto por estes autores para um grupo de espécies neotropicais de Eucerini. Ao revisar as espécies de Gaesischia, URBAN (1968) colocou a espécie de Ducke neste gênero e redescreveu somente a fêmea. A nova combinação, Alloscirtetica labiatarum (Ducke, 1910) só foi possível após estudo dos machos coletados no nordeste brasileiro. Alloscirtetica Holmberg, 1909, é um gênero rico em espécies no CHILE e ARGENTINA. As primeiras espécies brasileiras foram dadas a conhecer por URBAN

${ }^{1}$ Contribuição no 1445 do Departamento de Zoologia, Universidade Federal do Paraná. ${ }^{2}$ Departamento de Zoologia, Universidade Federal do Paraná. Caixa Postal 19020, 81531-980 Curitiba, Paraná, Brasil. Bolsista do CNPq. 
(1971): Alloscirtetica clypeata, do Paraná e Minas Gerais, registrada também na ARGENTINA e Alloscirtetica alvarengai, do Pará e Maranhão. A descrição do macho de Thygater armandoi, coletado em Camaragibe, Pernambuco, completa o trabalho.

Alloscirtetica labiatarum (Ducke, 1910) comb. nov.

(Figs 1e 2)

Eucera labiatarum Ducke, 1910, Rev. d'Ent., Caen 28: 92.

Gaesischia (Gaesischia) labiatarum Michener, LaBerge \& Moure, 1955, Dusenia 6 (6): 222. Urban, 1968. Bol. Univ. Fed. Paraná, Zoologia, III (4): 102.1.

\section{MACHO}

Comprimento aproximado $8,51 \mathrm{~mm}$; comprimento da asa a partir do esclerito costal $6,22 \mathrm{~mm}$; largura da cabeça $3,23 \mathrm{~mm}$; comprimento do olho $1,83 \mathrm{~mm}$; comprimento máximo dos dois flagelômeros basais $0,15 \mathrm{~mm}$ e $0,78 \mathrm{~mm}$.

Tegumento preto exceto o labro, grande parte das mandíbulas e do clípeo amarelo-claros; as mandíbulas com com nódoa amareloescura na área castanho-amarelada do terço apical; o clípeo com a grande mácula amarela orlada de preto ao longo da sutura epistomal, estreitamente nos lados e alargada em direção ao ramo transversal da sutura epistomal, unindo finamente um lado ou outro. Antenas castanhas dorsalmente e com a face ventral de um castanho pálido. Pernas com predominância de castanho-amarelado, menos os artículos basais pretos, nas anteriores até o fêmur e uma estria alongada também preta nas tíbias; nas medianas e posteriores só a base dos fêmures e a estria alongada no lado externo das tíbias, pretas. Tergos e esternos com larga margem esbranquiçada translúcida, o distal ferrugíneo.

Pilosidade creme, porém no mesoscuto e escutelo com pêlos esbranquiçados com a ponta enegrecida; do segundo ao quarto tergo 
com faixa discal de pêlos muito curtos enegrecidos; longa e densa na cabeça e mesosoma, curta e decumbentne porém densa nos tergos, estes com cerdas semi-decumbentes intercaladas, as cerdas um pouco alaranjadas.

Palpos maxilares com o segundo e terceiro artículos longos e finos, o quarto quase igual à metade do terceiro e os dois apicais muito curtos; clípeo abaulado sem carena e denso pontuado; flagelômeros sem carenas, o basal igualando o comprimento do pedicelo e menor que $1 / 5$ do comprimento do segundo; fêmures medianos sem angulosidade basal, trocanteres posteriores com o bordo arredondado, basitarsos posteriores não ultrapassando a articulação com o tarsômero seguinte; sétimo tergo com o bordo livre carenado e arredondado, levemente emarginado no meio; placa pigidial pontuada, limitada aos lados por concavidades convergentes para a ponta; sexto esterno com pêlos muito curtos convergentes para o meio, sem formar tufo.

Distribuição geográfica — BRASIL, Ceará, Caridade (localidade-tipo), Paraíba, Sta. Luzia, Germania. Novas ocorrências: Sergipe, Canindé do São Francisco, Debora Moura col.; Rio Grande do Norte, Serra Negra do Norte, C. Schlindwein col.

\section{Comentário}

Alloscirtetica labiatarum tem em comum com A. clypeata os caracteres do sétimo tergo e do sexto esterno além da grande área subapical amarela do clípeo, embora em A. clypeata a mácula amarela do clípeo seja mais curta, ultrapassando a metade do comprimento do clípeo apenas no meio. Além disso, o porte maior (comprimento total cerca de $10 \mathrm{~mm}$ e as asas com pouco mais de $8 \mathrm{~mm}$ ) e a ausência de faixas pilosas enegrecidas na base dos tergos separam A. clypeata de A. labiatarum. A. alvarengai tem a placa pigidial brilhante levemente carenada, com as margens convergindo para a ponta e terminando em forma de lâminas em uma projeção distal larga e curta; sexto esterno com tufo discal e áreas laterais glabras 
muito estreitas; flagelômero basal alongado, cerca de duas vezes o comprimento do pedicelo e de um terço do segundo flagelômero.

Thygater armandoi Urban, 1999

(Figs 3 e 4)

Thygater armandoi Urban, 1999: 219.

\section{MACHO}

A seguir é descrito o macho desta espécie, pela primeira vez, tendo em mão espécimes coletados em Camaragibe, Pernambuco.

Comprimento aproximado $12 \mathrm{~mm}$, comprimento da asa anterior a partir do esclerito costal $9,03 \mathrm{~mm}$; largura da cabeça $4 \mathrm{~mm}$; comprimento mínimo da área malar $0,32 \mathrm{~mm}$; largura da mandíbula na base 0,56 . Tegumento enegrecido menos o labro amarelo-pálido; lado ventral do flagelo e os tarsômeros intermediários castanhoamarelados, os basitarsos enegrecidos.

Pilosidade predominante castanho-enegrecida. Branca em grande parte da cabeça; vértice e parte adjacente das paroculares castanho-enegrecidos e uma área com pêlos brancos e enegrecidos nas paroculares inferiores. No mesoscuto e escutelo castanha com orla branca; na parte dorsal do propódeo, face ventral dos mesepisternos e em grande parte das pernas, branca; passando a enegrecida nas tíbias e tarsos medianos e posteriores; no tergo basal branca, nos demais tergos castanho-enegrecida, com mescla de pêlos brancos e pretos nos distais; branca nos esternos.

Trocanteres anteriores com franja longa de cerdas justapostas e com poucas ramificações, a franja cerca de 1/3 mais longa que a pilosidade adjacente da face posterior dos fêmures; basitarsos posteriores com depressão rasa na face externa, os lados paralelos, sem projeção distal, mais estreitos que $1 / 5$ do seu comprimento; face ventral dos mesepisternos com pilosidade curta e densa; segundo esterno com pequena área médio-apical desprovida de pêlos, no terceiro e quarto esternos sem área médio-apical glabra, com pêlos muito curtos na margem e franjas laterais. 

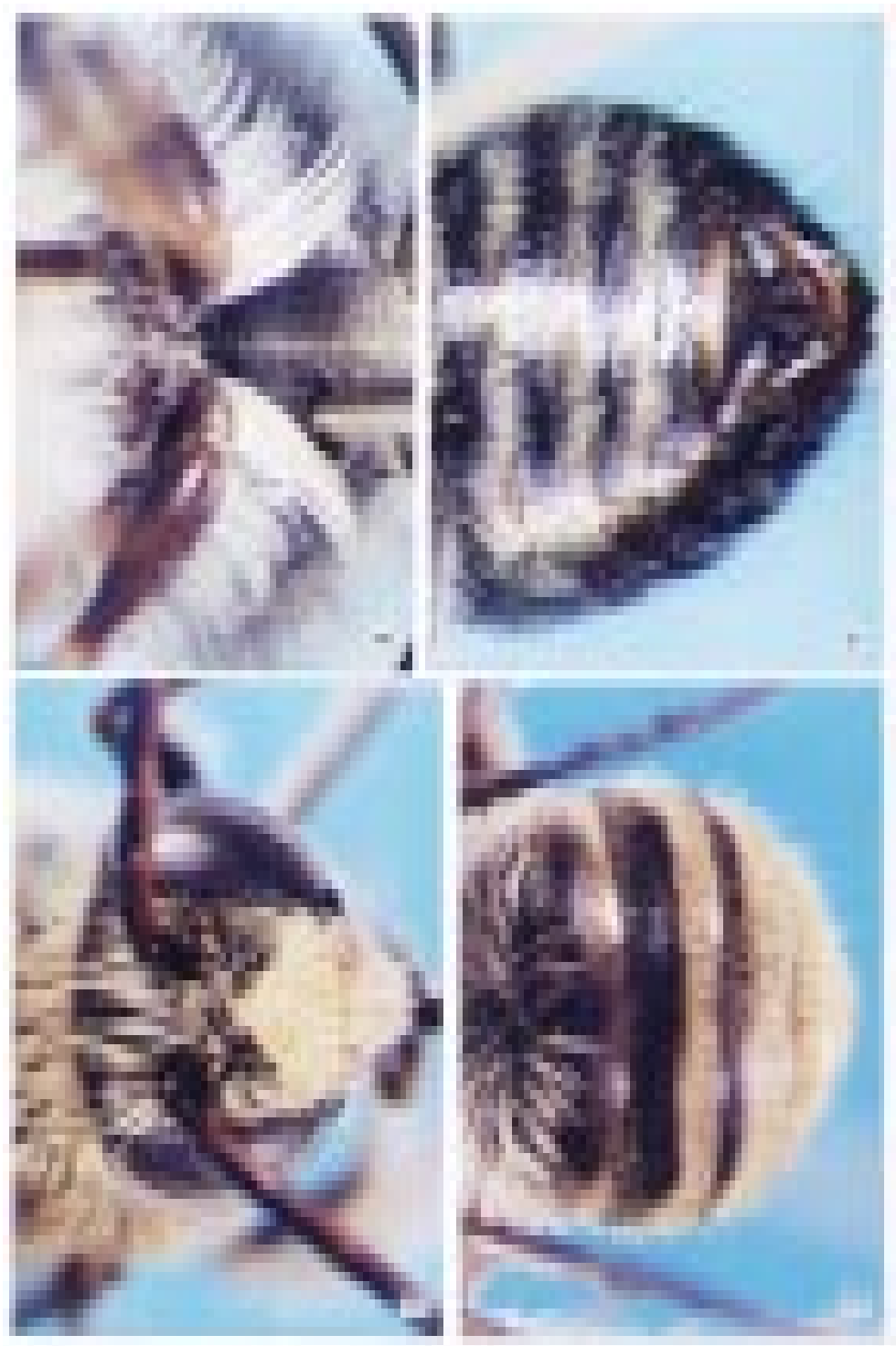

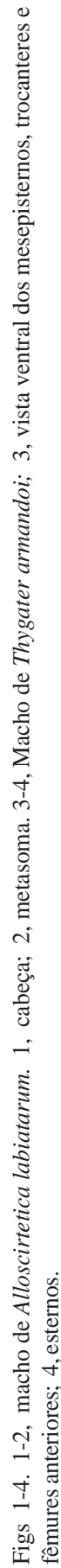




\section{Comentário}

T. armandoi e T. analis (Lepeletier, 1841) têm franja cerdosa longa nos trocanteres anteriores, entretanto em $T$. analis a pilosidade da face posterior dos fêmures tem o mesmo comprimento que a franja cerdosa, diminuindo em direção à base dos fêmures e, o segundo e terceiro esternos têm área glabra médio-apical larga, ocupando o terço mediano do bordo.

Distribuição GeOGRÁficA - BRASIL, Pernambuco, Minas Gerais, Rio de Janeiro e São Paulo. São ocorrências novas: Camaragibe, Pernambuco, C. Schlindwein leg. e São Paulo, São Paulo, I. Alves dos Santos leg.

Agradecimentos - Ao Dr. Clemens Schlindwein, Departamento de Botânica, Universidade Federal de Pernambuco, à Dra. Isabel Alves dos Santos, Departamento de Biologia da Universidade do Extremo Sul Catarinense, pela doação dos espécimens e ao Dr. Albino Morimasa Sakakibara pelas fotos que ilustram o trabalho.

\section{RESUMO}

Alloscirtetica labiatarum (Ducke, 1910) comb. nov. é proposto e a redescrição do macho é apresentada para facilitar comparações com as espécies brasileiras deste gênero. Completando o trabalho é descrito o macho de Thygater armandoi Urban, 1999.

Palavras chave: Hymenoptera, Anthophoridae, Eucerini, Alloscirtetica, Thygater, taxonomia.

\section{SUMMARY}

Alloscirtetica labiatarum (Ducke, 1910) comb. nov. is proposed and the redescription of the male is presented to make easy comparisons with the remainder Brazilian species of this genus. The male from Thygater armandoi Urban, 1999, is described.

Key Words: Hymenoptera, Anthophoridae, Eucerini, Alloscirtetica, Thygater, taxonomia. 


\section{RÉSUMÉ}

Alloscirtetica labiatarum (Ducke, 1910) comb. nov. est proposé et la redescription du mâle est presenté pour rendre facile comparaisons avec les espèces de ce genre du Brèsil. Le mâle de Thygater armandoi Urban, 1999, est décrit pour la première fois.

CLés mots: Hymenoptera, Anthophoridae, Eucerini, Alloscirtetica, Thygater, taxonomie.

\section{BIBLIOGRAFIA}

Ducke, A., 1910. Contribution a la connaissance de la Faune hyménoptérologique du Nord-Est du Brésil. Revue d'Entomologie, Caen. 28: 92

Michener, C. D. , W. E. La Berge \& J. S. Moure. 1955. Some American Eucerini Bees. Dusenia 6 (6): 213-230.

Urban, D. 1968. As espécies de Gaesischia Michener, LaBerge \& Moure, 1955. (Hymenoptera, Apoidea). Bol. Univ. Fed. Paraná, Zool. 3 (4): 79-129.

Urban, D. 1971. As espécies de Alloscirtetica Holmberg, 1909 (Hymenoptera, Apoidea). Bol. Univ. Fed. Paraná, Zool. 3 (16): 307-369.

Recebido em 9.10.2002. 


\section{Em branco}

